\title{
Editorial
}

\section{Agronomy-A Multidisciplinary and Open Access Journal}

\section{Peter Langridge}

Founding Editor-in-Chief of Agronomy, Australian Centre for Plant Functional Genomics, University of Adelaide, Urrbrae, SA5064, Australia; E-Mail: peter.langridge@acpfg.com.au

Received: 20 January 2011 / Accepted: 21 January 2011 / Published: 21 January 2011

Agronomy is a highly multidisciplinary area of science. It includes all aspects of science and technology related to the production and utilization of plants for food, feed, fuel, fiber and even land reclamation. In many respects, agronomy represents the integration of activities and disciplines ranging from genetics, chemistry and biotechnology to ecology, soil science and meteorology.

The agricultural industries have shown spectacular improvements over the past 50 years. Since the introduction of the Green Revolution crops in the early 1960s, there has been a linear increase in crop production from 1.84 billion tonnes to 4.38 billion tonnes in 2007, an increase of 138 percent but on a total area of agricultural land that grew by only 11 percent. This growth occurred over a period where the human population grew from 3 to 6.7 billion. Food production is still dominated by the cereals, which make up around 50 percent of global food production. Altogether, crops make up around 80 percent of human food.

Three factors have underpinned the rapid improvements in crop production: improved varieties resulting from the development and adoption of new breeding technologies, a large expansion in area under irrigation with resultant large increases in yield, and finally, the widespread use of fertilizers, particularly nitrogen and phosphorus. Of these, only the first can be regarded as sustainable since water availability is declining and the use of fertilizers is associated with environmental problems. However, there are significant opportunities to improve the efficiency of water and fertilizer use and modify farming practices to increase productivity.

The world population is predicted to grow to around nine billion by 2050 and the World Food Summit on Food Security in 2009 set a target of 70 percent increased food production over the next 30 years, which would require an annual rate of increase of 44 million tonnes. This is an ambitious target since there are some serious concerns about the viability of existing production systems and the sustainability of the current growth rates. Further, the predicted environmental changes associated with climate change are expected to have an overall negative effect on agricultural production with serious crop declines in some countries. 
The increasing demand for meat has placed further pressure on the pasture and grain industries. In developed countries almost 70 percent of grain production now goes to animal feed. The redirection of grain for non food uses has also occurred due to the growth of the biofuels industries in several countries as a result of a range of subsidies. This has led to an increased demand for cereals and oilseeds, particularly in the United States and the European Union, and is believed to have contributed to increases in food prices. In addition, the rapid increases in urbanization and loss of peri-urban land has had an impact on production, particularly of horticultural crops.

Ensuring adequate supplies of food, feed and fiber will demand the development and delivery of new technologies to increase production on limited arable land and without relying on increased water and fertilizer use. Greater climatic instability now seems inevitable and we know that future production increases will occur in a resource constrained environment. The future costs of energy, water, fertilizers and carbon will strongly influence the production framework.

We need to adapt our agricultural and food industries to the new production environment. The key advances are expected to come from new breeding technologies and improved resource management systems. Significant technical advances will help ensure efficient production. Of course, technology will provide only one component of the solution. Many other factors are important, such as population, infrastructure and political stability.

Many of the objectives, strategies and approaches required to maintain and increase crop production are controversial. We have seen major technological advances in recent years but there have been significant issues associated with technology delivery and acceptance. The aim of this open access journal is to provide a forum to present results, ideas and debate issues related to crop production. Agronomy will publish results of original research, reviews, short communications and commentaries. Since there is no restriction on paper length, detailed experimental data and methods can be presented. We are also keen to prepare special issues that provide a comprehensive analysis of many of the key issues and hot topics in crop production. The editorial board has broad expertise covering most aspects of agronomy and is committed to ensuring that Agronomy publishes high quality articles that are at the forefront of agricultural science. Our objective is to cover the full spectrum of agronomic and crop research including broad acre, horticultural, biofuel and fiber crops. The success of this endeavor will depend upon the research community, we therefore hope you will actively participate by submitting high quality papers to Agronomy, provide suggestions of special issues and give general feedback on the objectives and progress of this journal.

(C) 2011 by the authors; licensee MDPI, Basel, Switzerland. This article is an open access article distributed under the terms and conditions of the Creative Commons Attribution license (http://creativecommons.org/licenses/by/3.0/). 